\title{
Die Haftung des Schiedsrichters in der internationalen Handelsschiedsgerichtsbarkeit
}

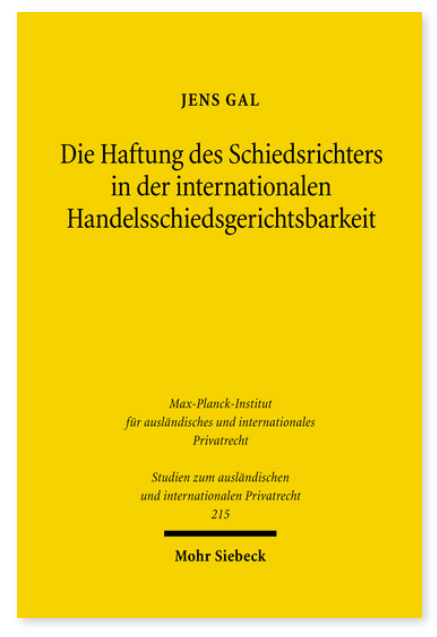

2009. XXII, 496 Seiten. StudIPR 215

ISBN 978-3-16-151400-5

DOI 10.1628/978-3-16-151400-5

eBook PDF 94,00€

ISBN 978-3-16-149813-8

fadengeheftete Broschur 94,00€
Mit stetig wachsender Zahl der Schiedsverfahren im internationalen Rechtsverkehr und zunehmender Verrechtlichung der Schiedsgerichtsbarkeit rückt auch der Schiedsrichter in seiner Funktion als Dienstleister vermehrt in das Blickfeld der Rechtswissenschaft. Hierbei gewinnt auch die Frage einer möglichen Haftung des Schiedsrichters deutlich an Interesse. Jens Gal vergleicht die in Deutschland, England, Frankreich, Österreich, der Schweiz und den Vereinigten Staaten von Amerika entworfenen Haftungsmodelle. Er bereitet das Thema in seinen unterschiedlichen Dimensionen - historisch, rechtsvergleichend und dogmatisch - auf und entwickelt eine kohärente Haftungssystematik. Das Augenmerk gilt zunächst dem als Haftungsgrundlage ausgemachten sogenannten Schiedsrichtervertrag und seiner dogmatischen Ausgestaltung. Im Anschluss hieran widmet sich der Autor möglichen haftungsauslösenden Pflichtverletzungen, wobei er seine besondere Aufmerksamkeit der Frage widmet, ob und inwieweit dem Schiedsrichter ein Haftungsprivileg zusteht und welche Pflichten von diesem Haftungsprivileg umfasst sind. Hierbei zeigt sich, dass es einem weltweiten Konsens entspricht, dass der Schiedsrichter nur in begrenztem Umfang - nämlich einem Richter gleich - haftbar gemacht werden kann. Obgleich das so entworfene Haftungsmodell ein nur beschränktes Haftungsrisiko für den Schiedsrichter birgt, zeigt der Autor abschließend Möglichkeiten auf - insbesondere Haftungsbegrenzung, Versicherungsdeckung und Rechtswahl - mittels deren Schiedsrichter ihr Risiko weiter minimieren können.

Jens Gal Studium der Rechtswissenschaft an der Goethe-Universität Frankfurt/Main; Dozent am Institute for Law and Finance in Frankfurt und an der Université Lumière II in Lyon; Inhaber einer Juniorprofessur für Europäisches Versicherungsrecht an der Goethe-Universität in Frankfurt/Main.
Jetzt bestellen:

https://mohrsiebeck.com/buch/die-haftung-des-schiedsrichters-in-der-internationalen-handelsschiedsgerichtsbarkeit9783161514005?no_cache=1

order@mohrsiebeck.com

Telefon: $+49(0) 7071-923-17$

Telefax: $+49(0) 7071-51104$ 